\title{
KETERAMPILAN BERPIKIR TINGKAT TINGGI/HOTS MAHASISWA PENDIDIKAN GEOGRAFI KELAS INTERNASIONAL TAHUN MASUK 2018 PADA MATA KULIAH HIDROLOGI
}

\author{
Eti Susanti', Nofrion ${ }^{2}$ \\ Program Studi Pendidikan Geografi \\ Fakultas Ilmu Sosial, Universitas Negeri Padang \\ Email: Etisusanti100@gmail.com
}

\begin{abstract}
ABSTRAK
Penelitian ini dilatarbelakangi adanya tuntutan HOTS mahasiswa Kelas Internasional sebagai kelas yang dirancang khusus untuk mewujudkan visi UNP menjadi universitas unggul di Asia Tenggaratahun 2020 dan dipilih mata kuliah Hidrologi dalam penelitiankarena Hidrologi memiliki ruanglingkupcukup luas dan komprehensif.Berdasarkan observasi awal diketahui presentasi mahasiswa hanya sekedar menghafal dan membaca materi, sertamenyalin materi tugas.Tujuan penelitian ini untuk mengetahui aktivitas belajar, presentasi dan kualitas tugas mahasiswa.Penelitian ini menggunakan metode deskriptif kuantitatifdanInstrumen penelitian berupa lembar observasi dancheck list. Penelitian ini menemukan bahwa (1)aktivitas belajar HOTS mahasiswa memiliki kategori baik dengan persentase ABL75\%-82\%, (2)presentasi tugas memiliki kategori kurang baik dan baik dengan persentase 50\%-70\%,(3)kualitas tugas mahasiswa mendapatkan kategori tidak baik dan kurang baik dengan persentase 48\%-53\% karena sebagian besar tugas mahasiswa hanyamengutip, menyatakan ulang, atau merujuk tanpa pengembangan, perbandingan, dan analisis dengan bahasasendiri.
\end{abstract}

Kata Kunci: Kelas Internasional, HOTS, Aktivitas Belajar, Presentasi, Kualitas Tugas.

\section{ABSTRACT}

This research is backed by the demands of HOTS international class students as a class specially designed to realize the vision of UNP to be the Superior University in Southeast Asia in 2020 and selected hydrological courses in research because Hydrology has a fairly broad and comprehensive scope. Based on an early observation, the student presentation simply memorized and read the material, as well as copying the task material. The purpose of this research is to know the learning activities, presentation and quality of student work. This research uses quantitative descriptive methods and research instruments in the form of an observation sheet and a check list. The study found that (1) the activity of learning HOTS students had a good category with a percentage of ABL 75\%-82\%, (2) Presentation of assignments had a category less good and good with a percentage of 50\%-70\%, (3) Quality of Duty students get the category Not good and less good with a percentage of 48\%-53\% because most of the student's work only quotes, restates, or refers without development, comparison, and analysis with its own language.

Keywords:International Class, HOTS, Learning Activities, Presentations, Quality of Tasks.

\footnotetext{
${ }^{1}$ Mahasiswa Program Studi PendidikanGeografi Fakultas Ilmu Sosial

${ }^{2}$ Dosen Jurusan Geografi Fakultas Ilmu Sosial, Universitas Negeri Padang
} 


\section{PENDAHULUAN}

Perkembangan

menuntut adanya peningkatan standar pendidikan baik output maupun outcome. Peningkatan standar tersebut dilakukan guna menghadapi persaingan yang sangat ketat dilingkup dunia. Salah satu usaha yang dilakukan dengan penyelenggaraan kelas internasional. Kelas Internasional dapat meningkatkan kualitas sumber daya manusia sehingga mampu menjawab tantangan zaman yang berubah-ubah serta mampu menciptakan SDM yang mampu bersaing pada tingkat regional, nasional maupun internasional. Salah satu perguruan tinggi negeri yang menyelenggarakan program ini yaitu Universitas Negeri Padang.

Universitas Negeri Padang menyelenggarakan Kelas Internasional pada 14 program studi salah satunya pada program studi Pendidikan Geografi. Program Kelas Internasional dirancang untuk menghasilkan lulusan yang bermutu serta mewujudkan visi UNP menjadi universitas yang unggul di Asia Tenggara tahun 2020. Oleh karena itu mahasiswa Kelas Internasional memiliki tuntutan yang lebih tinggi dibandingkan kelas reguler terutama dalam penggunaan bahasa serta keterampilan berpikir tinggi tinggi.

Menurut Rosnawati (2009)

High Order Thinking Skill/HOTS adalah keterampilan berpikir yang tidak sekedar memerlukan keterampilan mengingat saja, tetapi juga memerlukan keterampilan lain yang lebih tinggi, misal keterampilan berpikir kreatif serta kritis. High Order Thinking Skill (HOTS) yaitu proses berpikir yang tidak hanya menghafal serta menyampaikan ulang informasi yang diketahui (Rofiah dkk, 2013). Keterampilan berpikir tingkat tinggi atau High Order Thinking Skill (HOTS) merupakan keterampilan menghubungkan/ memanipulasi/ mentransformasi pengetahuan dan pengalaman dalam pikiran kita untuk berpikir kreatif dan kritis sebagai upaya untuk mengambil keputusan dan menyelesaikan masalah yang baru ditemui (Brookhart, 2010).

Seluruh mata kuliah Pendidikan Geografi memerlukan keterampilan berpikir dalam memahaminya. Hal itu menyebabkan beberapa mahasiswa kesulitan dalam memahami materi sehingga mutu dan kemampuan mahasiswa belum memiliki hasil yang memuaskan. salah satu cabang ilmu geografi yang memerlukan keterampilan berpikir tingkat tinggi adalah mata kuliah Hidrologi.

Hidrologi dipilih peneliti sebagai objek mata kuliah dalam penelitian karena Hidrologi merupakan salah satu mata kuliah pada program studi Pendidikan Geografi yaitu sebagai cabang geografi fisik dimana geografi memiliki empat cabang ilmu yaitu geografi fisik, sosial, pendidikan, dan 
teknik. Mata kuliah mahasiswa Kelas Internasional tahun masuk 2018 pada semester 2 terdiri dari Geografi Sosial, Geografi Pendidikan, Hidrologi, Geomorfologi, Geografi Indonesia, Handasah, Geografi Tanah dan Biogeogafi. Peneliti memilih Hidrologi sebagai objek penelitian bukan berarti mata kuliah lain tidak memerlukan Keterampilan Berpikir Tingkat Tinggi/HOTS dalam pembelajaran namun dalam penelitian peneliti juga memerlukan sistim yang mendukung salah satunya dari hasil diskusi peneliti dengan dosen yang juga meneliti HOTS menyarankan untuk mengambil mata kuliah Hidrologi sebagai cabang fisik ilmu Geografi. Selain pertimbangan dari dosen, peneliti tertarik dengan mata kuiah Hidrologi karena ruang lingkup Hidrologi cukup luas. Ruang lingkup mata kuliah Hidrologi mencakup(1) pengukuran, mencatat, dan publikasi data dasar, 2)deskripsi propertis, fenomena, dan distribusi air di daratan, 3)analisa data untuk mengembangkan teori-teori pokok yang ada pada Hidrologi, 4) aplikasi teori-teori Hidrologi untuk menyelesaikan masalah praktis. Selain itu kemudahan akses penelitian juga menjadi alasan peneliti, kemudahan tersebut diperoleh karena dosen pengampu mata kuliah Hidrologi sudah menyetujui agar kelas nya dijadikan sebagai kelas penelitian
HOTS sangat diperlukan dalam perguruan tinggi terutama pada mahasiswa tahun masuk 2018 yang merupakan mahasiswa yang baru memasuki pendidikan tinggi. Hal tersebut agar mahasiswa tahun masuk 2018 terbiasa berlatih menggunakan keterampilan berpikir tingkat tinggi, kritis,serta kreatif untuk menyelesaikan permasalahan maupun soal-soal tipe HOTS.

Berdasarkan observasi awal di Universitas Negeri Padang menunjukkan bahwa presentasi mahasiswa dalam diskusi kelompok hanya membacakan slide dan makalah,dukungan data/ fakta/ contoh masih kurang serta analisis sesuai teori/ konsep masih kurang, selain itu respon mahasiswa saat diberi kesempatan bertanya maupun ketika ditanya juga masih minim. Hal ini mengindikasikan bahwa mahasiswa pada proses pembelajaran terutama dalam diskusi, penyaji maupun audiens sama-sama belum memahami materi yang dipelajari. Penyaji hanya menghafal dan membacakan materi. Makalah yang dibuat kebanyakan sekedar menyalin dari internet tanpa menbacanya terlebih dahulu sehingga ditemui isi makalah yang tidak sesuai dengan daftar pustaka.

Berdasarkan kenyataan- diatas, penulis tertarik untuk melakukan penelitian berjudul "Keterampilan Berpikir Tingkat Tinggi /HOTS Mahasiswa Pendidikan Geografi 
Kelas Internasional Tahun Masuk 2018 pada Mata Kuliah Hidrologi”

\section{METODE PENELITIAN}

Penelitian ini merupakan jenis penelitian deskriptif kuantitatif. Menurut Mukhtar(2013) menyatakan bawa penelitian deskriptif adalah penelitian dengan mengumpulkan informasi tentang perilaku subjek penelitian pada periode tertentu. Menurut Sugiyono (2006) penelitian deskriptif kuantitatif adalah metode penelitian dengan cara mendapatkan data berbentuk angka dan dianalisis sesuai dengan metode statistik yang digunakan lalu diinterpretasikan.

Populasi dalam penelitian ini adalah mahasiswa Kelas Internasional angkatan 2018 Program Studi Pendidikan Geografi yang mengambil mata kuliah Hidrologi di UNP. Penentuan sampel dilakukan dengan teknik total sampling atau sampel jenuhyaitu teknik pengambilan sampel dimana seluruh anggota populasi dijadikansampel (Sugiyono,2014).Sampel pada penelitian ini adalah mahasiswa Pendidikan Geografi Kelas Internasional tahun masuk 2018 pada mata kuliah Hidrologi yang berjumlah 13 orang.

Metode pengumpulan data penelitian yaitu dokumentasi dan observasi. Metode observasi merupakan metode pengumpulan data dengan cara mengamati secara langsung dilapangan. Observasi dilakukan untuk memperoleh data aktivitas belajar dan presentasi tugas mahasiswa. Metode dokumentasi digunakan untuk melengkapi data yang berhubungan dengan kualitas tugas mahasiswa.

Untuk lebih jelasnya maka dapat dilihat pada tabel berikutini.

Tabel 1. Metode pengumpulan data

\begin{tabular}{ccccc}
\hline No & Metode & Sasaran & Alat & Analisis \\
\hline 1 & Observasi & Aktivitas belajar & Lembar observasi & Persentase \\
\hline 2 & Dokumentasi & Presentasi kelas & Lembar observasi & Persentase \\
\cline { 2 - 5 } & & Kualitas tugas & Lembar chek list & Persentase \\
\hline
\end{tabular}

Sumber:Pengolahan Data Primer 2019

Teknik analisis data dalam penelitian ini yaitu teknik deskriptif persentase. Berikut tabel kriteria hasil penelitian aktivitas belajar, presentasi dan kualitas tugas:

Tabel 2. Kriteria Deskriptif Persentase (Aktivitas Belajar)

\begin{tabular}{clc}
\hline NO & \multicolumn{1}{c}{ Interval } & Kriteria \\
\hline 1 & $87,51 \%-100,00 \%$ & Sangat Baik \\
\hline 2 & $75,01 \%-87,50 \%$ & Baik \\
\hline 3 & $62,51 \%-75,00 \%$ & Kurang Baik \\
\hline 4 & $50,00 \%-62,50 \%$ & Tidak Baik \\
\hline
\end{tabular}

Sumber:Pengolahan Data Primer 2019

Tabel 3. Kriteria Deskriptif Persentase (Persentase Tugas)

\begin{tabular}{|c|c|c|}
\hline $\mathrm{NO}$ & Interval & Kriteria \\
\hline 1 & $81,26 \%-100,00 \%$ & Sangat Baik \\
\hline 2 & $62,51 \%-81,25 \%$ & Baik \\
\hline 3 & $43,76 \%-62,50 \%$ & Kurang Baik \\
\hline 4 & $25,00 \%-43,75 \%$ & Tidak Baik \\
\hline
\end{tabular}

Sumber:Pengolahan Data Primer 2019 
Tabel 4. Kriteria Deskriptif Persentase (Kualitas Tugas)

\begin{tabular}{ccc}
\hline NO & \multicolumn{1}{c}{ Interval } & Kriteria \\
\hline 1 & $83,26 \%-100,00 \%$ & Sangat Baik \\
\hline 2 & $66,51 \%-83,25 \%$ & Baik \\
\hline 3 & $49,76 \%-66,50 \%$ & Kurang Baik \\
\hline 4 & $33,00 \%-49,75 \%$ & Tidak Baik \\
\hline Sumber:Pengolahan Data Primer 2019 & ABL & sebagai kegiatan yang
\end{tabular}

\section{HASIL DAN PEMBAHASAN}

\section{Aktivitas Belajar}

Penelitian aktivitas belajar dilakukan untuk mengetahui tingkat keterampilan berpikir mahasiswa baik berupa aktivitas belajar dasarmaupun aktivitas belajar lanjut, sesuai dengan Nofrion (2018) yang menyatakan aktivitas belajar terdiri dari Aktivitas Belajar Dasar (ABD) yang mengasah LOTS dan Aktivitas Belajar Lanjut (ABL) yang mengembangkan HOTS.
ABL sebagai kegiatan yang mengembangkan HOTS terdiri dari kegiatan mengolah/ menganalisis, mengkomunikasikan/ Berdialog, dan mendiskusikan/ berkolaborasi, hal itu sesuai dengan Nofrion,dkk (2019) yaitu aktivitas belajar HOTS terdiri dari analyzing, discuss, formulate, comunicate, colaboratie, and reflect.

Aktivitas belajar mahasiswa pendidikan geografi Kelas Internasional tahun masuk 2018 pada mata kuliah Hidrologi akan ditunjukkan pada diagram di bawah ini:

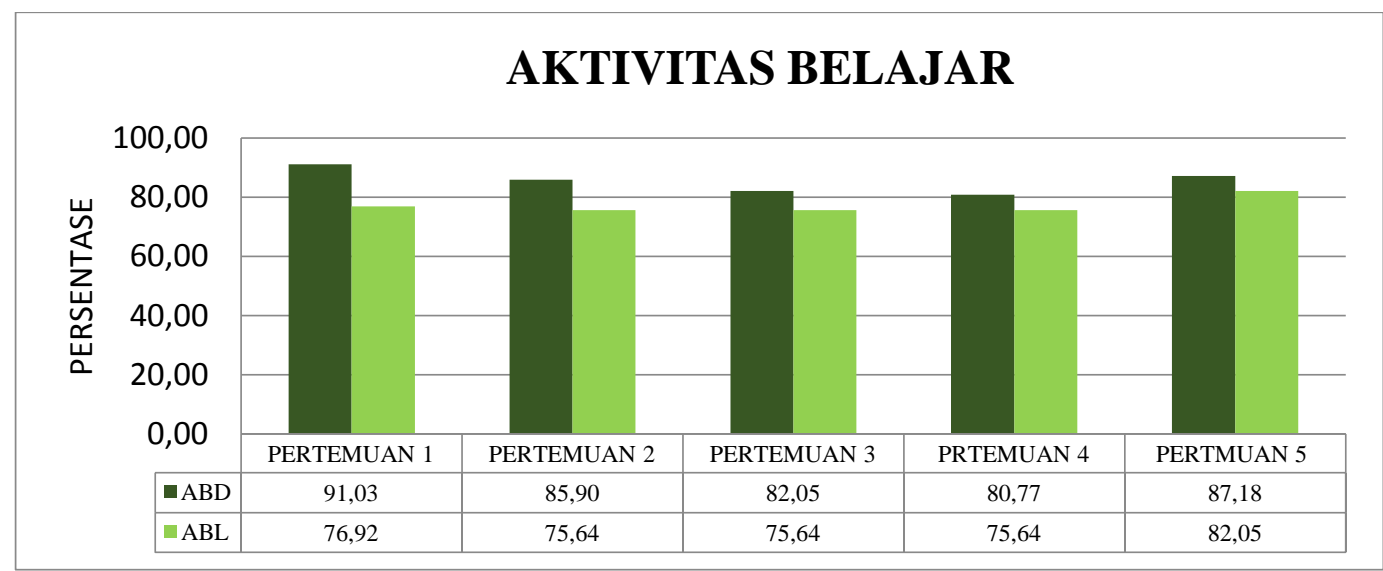

Gambar 1. Diagram aktivitas belajar mahasiswa pendidikan geografi Kelas Internasional tahun masuk 2018 pada mata kuliah Hidrologi.

Berdasarkan diagram pada gambar 1 menunjukkan bahwa Aktivitas Belajar Dasar /ABD lebih banyak dilakukan oleh mahasiswa Pendidikan Geografi Kelas Internasional tahun masuk 2018 pada mata kuliah Hidrologi
Aktivitas belajar dasar memiliki kategori sangat baik dan baik dengan persentase $80 \%-91 \%$ begitu juga dengan aktivitas lelajar lanjut sehingga dapat disimpulkan bahwa aktivitas belajar HOTS memiliki kategori baik dengan 
persentase $75 \%-82 \%$ meskipun skor persentase tidak stabil.

ABL/Aktivitas Belajar Dasarsebagai aktivitas yang dapat mengembangkan HOTS memiliki kategori baik maka dapat disimpulkan bahwa aktivitas belajar HOTS terlaksana dengan baik.

Berikut persentase aktivitas mengamati, menanya/ mencoba dan mengumpulkan/ mencari sebagai aktivitas belajar dasar yang mengarah pada pembelajaran LOTS serta persentase aktivitas mengolah/ menganalisis, mengkomunikasikan/ berdialog, dan mendiskusikan/ berkolaborasi sebagai aktivitas belajar lanjut yang mengarah pada pembelajaran HOTS:

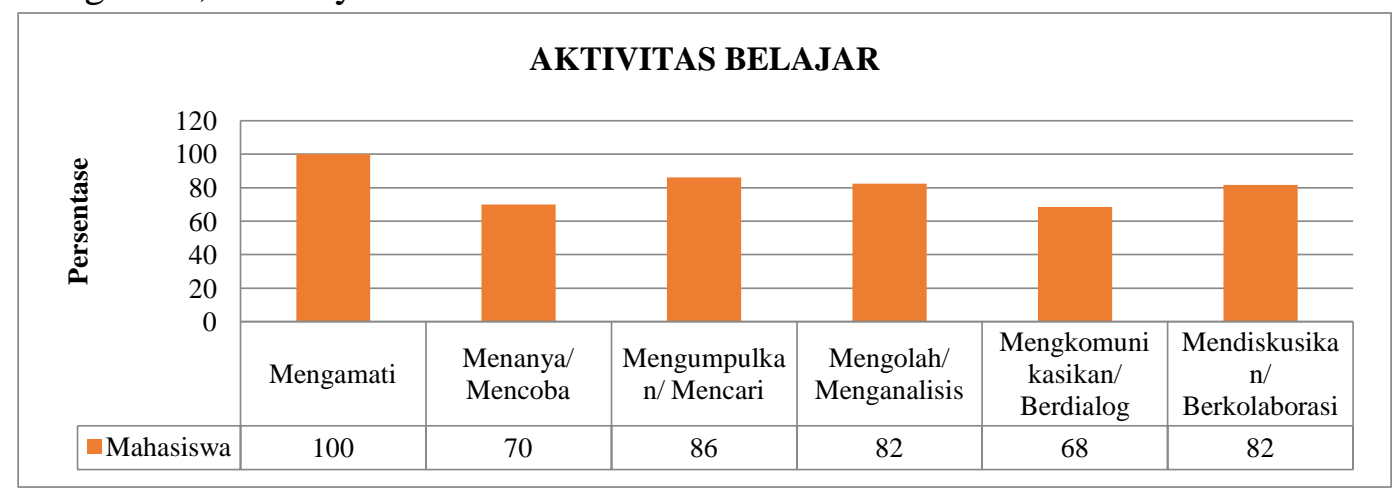

Gambar 2. DiagramAktivitas Belajar

Berdasarkan diagram yang ditunjukan oleh gambar 2 diatas maka dapat diketahui aktivitas belajar yang belum terlaksana dengan baik, selain itu juga dapat dilihat aktivitas belajar yang memiliki persentase tertinggi.

Saat melaksanakan Aktivitas

Belajar Dasar/ ABD tingkat partisipasi mahasiswa yang terendah terdapat pada aktivitas menanya/ mencoba dengan persentase $70 \%$. Sedangkan Aktivitas Belajar Lanjut/ABL tingkat partisipasi mahasiswa yang terendah terdapat pada aktivitas mengkomunikasikan/ berdialog dengan persentase $68 \%$.

Selain itu gambar 2 diatas juga menunjukkan bahwa pada ABD diketahui bahwa aktivitas yang memiliki persentase tertinggi adalah aktivitas mengamati sebagai yaitu dengan melihat (seperti membaca atau menyimak), mendengarkan, maupun melakukan kegiatan dengan maupun tanpa menggunakan alat bantu. Sedangkan pada ABL diketahui bahwa aktivitas mengolah/ menganalisis, dan mendiskusikan/berkolaborasi memiliki persentasi sama-sama tinggi yaitu dengan persentase $82 \%$.

\section{Persentase Tugas}

Penelitian tentang presentasi tugas dilakukan untuk mengetahui keterampilan berpikir tingkat tinggi atau High Order Thinking Skills (HOTS) mahasiswa Pendidikan Geografi Kelas Internasional tahun masuk 2018 pada mata kuliah 
Hidrologi dilihat dari cara mahasiswa menyampaikan hasil diskusi di depan kelas.

Aspek yang dinilai dari presentasi kelas antara lain organisasi dan sistematika presentasi, isi presentasi, teknik presentasi, media presentasi dan penggunaannya, serta kerja tim/ kekompakan. Hal itu sesui dengan Nofrion (2017) dalam Hibah
Revitalisasi Kurikulum dan Bahan Ajar Kemenristek Dikti Tahun 2016 dan 2017.

Penelitian dilakukan terhadap 13 orang mahasiswa Pendidikan Geografi Kelas Internasional tahun masuk 2018 pada mata kuliah Hidrologi yang dibagi menjadi 4 kelompok. Data skoring aktivitas belajar akan disajikan pada grafik berikut:

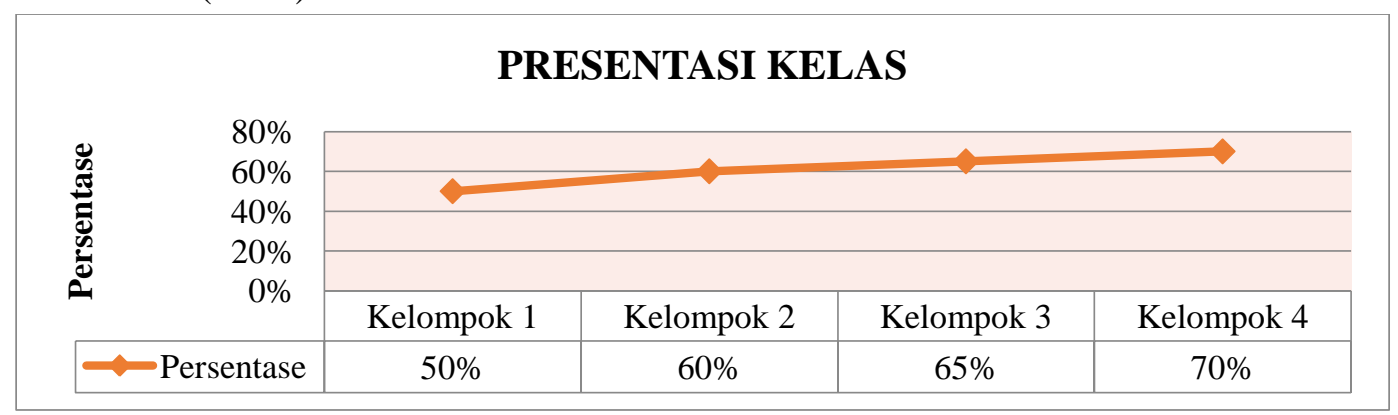

Gambar 3.Grafik Presentasi Tugas

Berdasarkangrafik presentasi tugas pada Gambar 3menunjukkan bahwa presentasi tugas mahasiswa Pendidikan Geografi termasuk kategori kurang baikdan baik yaitu dengan persentase antara 50\%-70\% sehingga dapat disimpulkan bahwa kegiatan presentasi kelas mahasiswa pendidikan geografi tahun masuk 2018 Kelas Internasional pada mata kuliah Hidrologi belum termasuk dalam HOTS.
Berikut diagram yang memperlihatkan persentase aspek yang dinilai dari presentasi kelas yang terdiri dari aspek organisasi dan sistematika presentasi, isi presentasi, teknik presentasi, media presentasi dan penggunaannya, serta kerja tim/ kekompakandari aspek organisasi dan sistematika presentasi, isi presentasi, teknik presentasi, media presentasi dan penggunaannya, serta kerja tim/ kekompakan:

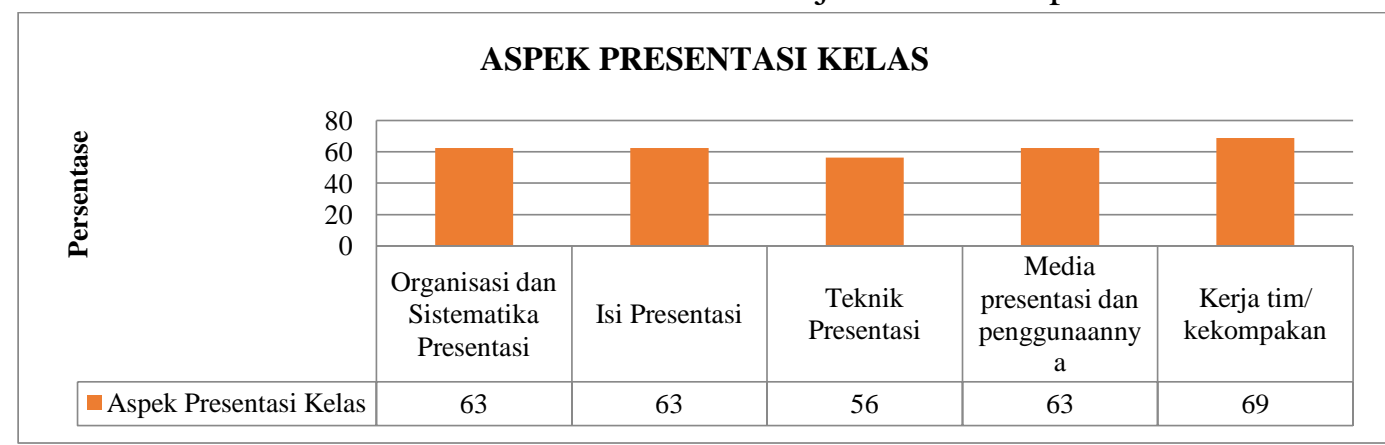

Gambar 4. Persentase Aspek Presentasi Kelas 
Berdasarkan diagram pada gambar 4 diketahui bahwa aspek presentasi kelas yang meimliki persentase tertinggi adalah aspek kerja tim/ kekompakan yaitu dengan persentase sebanyak $69 \%$. Sedangkan aspek presentasi kelas yang memiliki persentase 56\% dimana mahasiswa belum menguasai teknik voice, verbal dan visualdalam memprentasikan tugas kelompok di depan kelas.

\section{Kualitas Tugas}

Tugas HOTS(High Order

Thingking Skills) tidak hanya mengacu pada kemampuan menghafal atau mengingat (recall), menyatakan kembali (restate), mengingat (remember) serta merujuk tanpa adanya alasan yang ilmiah (recite).

Berikut tabel hasil observasi kualitas tugas yang dinilai berdasarkan tugas yang mengarah pada LOTS, MOTS atau HOTS.

Tabel 5. Persentase Kualitas Tugas

\begin{tabular}{ccc}
\hline & KUALITAS TUGAS & \\
\hline TUGAS & PERSENTASE & KATEGORI \\
\hline Tugas 1 & $51,28 \%$ & Kurang Baik \\
\hline Tugas 2 & $53,85 \%$ & Kurang Baik \\
\hline Tugas 3 & $48,72 \%$ & Tidak Baik
\end{tabular}

Sumber:Pengolahan Data Primer 2019

Berdasarkan tabel 5diatas menunjukkan bahwa sebagian besar kualitas tugas mahasiswa memiliki kategori kurang baik dengan persentase 48\%-53\%. karena tugas mahasiswa hanya berupa kutipan, dan menyatakan kembali, atau merujuk pada sumber yang digunakan tanpa mengganti kalimat serta belum nampak pengembangan/ perbandingan/ analisis dengan bahasa sendiri.

Selain itu berdasarkan hasil penelitian menunjukkan sebagian besar mahasiswa membuat tugas makalah pada tingkat rendah/LOTS dan sedang/MOTS. Hal tersebut sesuai dengan Kemendikbud (2017) yang menyatakan bahwa tugas HOTS adalah instrument atau alatukur yang dipakai untuk mengukur keterampilan berpikir tingkat tinggi, yaitu keterampilan berpikir yang tidak sekedar mengingat/ recall, atau menyatakan ulang/ restate, atau merujuk tanpa adanya pengolahan/ recite. Soal HOTS/ High Order Thinking Skill pada asesmen mengukur keterampilan: 1) transfer dari satu konsep kepada konsep yang lainnya, 2) memproses serta menerapkan sebuah informasi, 3) mencari hubungan berbagai informasi yang beragam, 4) menggunakan sebuah informasi untuk menyelesaikan suatu masalah, dan 5) menelaah sebuah ide serta informasi dengan kritis.

\section{KESIMPULAN}

Berdasarkan data hasil penelitian dan pembahasan yang telah jelaskan maka dapat ditarik kesimpulan bahwa aktivitas belajar 
mahasiswa pendidikan geografi tahun masuk 2018 Kelas Internasional pada mata kuliah Hidrologi yang mengarah pada kemampuan berpikir tingkat tinggi/ HOTS (High Order Thinking Skills) sudah terlaksana dengan baik yaitu dengan persentase ABL antara $75 \%$ $82 \%$. Dan dari penelitian yang telah dilakukan dapat diketahui bahwa aktivitas mengamati dengan persentase $100 \%$ dimana mahasiswa selalu melakukan aktivitas mengamati berupa mendengar maupun melihat. Sedangkan aktivitas belajar dengan persentase terendah adalah aktivitas mengkomunikasikan /berdialog dengan persentase $68 \%$.

Sedangkan pada kegiatan presentasi tugas mahasiswa memiliki kategori kurang baik dan baik yaitu dengan persentase antara 50\%-70\% dan pada pesentasi kelas aspek yang memiliki presentase terendah adalah pada aspek teknik presentasi dan persentase tertinggi ada pada aspek kerja tim/kekompakan.

Hal yang sama juga terlihat pada kualitas tugas mahasiswa dimana sebagian besar berupa kutipan, menyatakan kembali, atau merujuk tanpa mengubah kalimat dari sumber serta belum nampak pengembangan, perbandingan maupun analisis dengan menggunakan bahasa sendiri atau tugas belum termasuk kedalam kategori tugas hasil berpikir tingkat tinggi/HOTS.
DAFTAR PUSTAKA.

Brookhart, S., M. (2010). How To Asses Higher Order Thinking Skill in Your Classroom. Virginia :ASCD

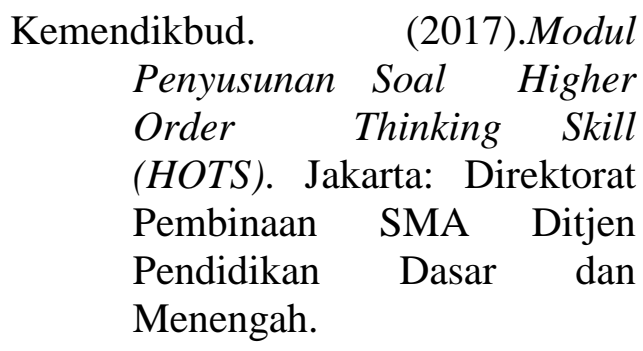

Mukhtar, 2013. Metode Praktis Penelitian Deskriptif Kualitatif. GP Press Group): Jakarta.

Nofrion. (2017). Implementasi Model Pembelajaran "Exo Olo Task"Berbasis Lesson Studypada Mata Pelajaran Geografi".Disertasi.

Nofrion, N. (2018, October 14). Panduan Pelaksanaan Model Pembelajaran EXO OLO TASK (Mengembangkan Keterampilan Berpikir Tingkat Tinggi (HOTS) Dalam Pembelajaran). Https://Doi.Org/10.31227/Osf .Io/Wh2mp

Nofrion, N. (2019, May 14). Flip Your Classroom: Flipped Classroom Melalui Penerapan Model Pembelajaran Exo Olo Task. https://doi.org/10.31227/osf.i o/qb9wz 
Rofiah, E., Aminah, N. S., dan Ekawati,

E.Y(2013)Penyusunan

Instrumen Tes

kemampuan berfikir Tingkat Tinggi Fisika pada siswa SMP Jurnal Pendidikan

Fisika, 1 (2), 17- 22.

Rosnawati. (2009). Enam Tahapan Aktivitas dalam Pembelajaran untuk Mendayagunakan Berpikir Tingkat Tinggi Siswa. Jurnal Edukasi, 1.

Sugiyono. 2006. Metode Penelitian Kuantitatif, Kualitatif, dan $R \& D$. Bandung: Alfabeta. 